Revista de la red interuniversitaria de estudios sobre las literaturas rioplatenses contemporáneas en Francia

Hors-série | 2019

Ricardo Piglia: Cierta idea de literatura

\title{
El camino de Ida, o la extranjería a partir de la lengua y de la relación con Hudson
}

\section{Jorge Bracamonte}

\section{OpenEdition}

\section{Journals}

Edición electrónica

URL: http://journals.openedition.org/lirico/7727

DOI: $10.4000 /$ lirico. 7727

ISSN: 2262-8339

Editor

Réseau interuniversitaire d'étude des littératures contemporaines du Río de la Plata

\section{Referencia electrónica}

Jorge Bracamonte, «El camino de Ida, o la extranjería a partir de la lengua y de la relación con Hudson », Cuadernos LIRICO [En línea], Hors-série | 2019, Puesto en línea el 12 febrero 2019, consultado el 09 mayo 2019. URL : http://journals.openedition.org/lirico/7727 ; DOI : 10.4000/lirico.7727

Este documento fue generado automáticamente el 9 mayo 2019.

\section{(c) $(1) \odot$}

Cuadernos LIRICO está distribuido bajo una Licencia Creative Commons Atribución-NoComercialSinDerivar 4.0 Internacional. 


\title{
El camino de Ida, o la extranjería a partir de la lengua y de la relación con Hudson
}

\author{
Jorge Bracamonte
}

\section{En otro país}

"Mi inglés me hacía sentirme indeciso y poco convincente"

Emilio Renzi en El camino de Ida

1 En El camino de ida (2013) de Ricardo Piglia (1940-2017), convergen múltiples aspectos de la extranjería, de lo extranjero como una manifestación de la Otredad, lo que a su vez es un tópico estructurador crucial de la poética de este escritor. La extranjería como alteridad se vuelve una manifestación notable en diversos textos a lo largo de la obra pigliana, hasta incluso su novela de 2013. Y casi siempre los personajes-voces, los actores ficcionales extranjeros, con cierta ajenidad inevitable a la cultura argentina, aparecen en las ficciones del escritor condensando diferentes aspectos de una especie particular de Otro. Esa especie particular de Otredad puede manifestarse en la extrañeza de lo cotidiano, que es evidente en la gestualidad, en los cuerpos y en una relación instintiva entre personajes, como ocurre en "La caja de vidrio" (Prisión perpetua, 1988); o bien en ese haz de miradas descentradoras de los lugares comunes de la historia argentina que en Respiración artificial (1980) problematizan desde lo literario y lo cultural, siendo decisiva entre esas miradas la perspectiva filosófica pesimista del polaco Tardewski, el ex discípulo del austríaco Ludwig Wittgenstein; o bien en el juego de tensiones convergentes en torno al puertorriqueño Tony Durán y al dazei Yoshio en Blanco nocturno (2010); o aun en el paroxismo de múltiples códigos de la extranjería que puebla La ciudad ausente (1993), donde tal vez todo se condense en el epítome de esa "isla" utópica del delta argentino que simultáneamente es como una Irlanda joyceana. 
2 Desde el punto de vista de la extranjería como Otredad, El camino de Ida resulta a su vez un caso paradigmático. Esto se aprecia, en primer lugar, por los actores ficcionales centralmente implicados y por los grandes segmentos de la diégesis. Así vemos, al inicio, a ese escritor argentino parcialmente reconocido, Emilio Renzi, quien atraviesa una crisis personal en Buenos Aires tras una separación conyugal y que es contratado por una prestigiosa universidad estadounidense de la Ivy League. Renzi acepta el ofrecimiento y viaja hacia los Estados Unidos cuando transcurren los primeros años de la presidencia de Clinton (presidente de 1993 a 1997 y de 1997 a 2001)1. El foco narrativo, la perspectiva de Emilio, central en la estructuración de todo el relato, manifiesta de modo recurrente su condición de estar accediendo a esa cultura Otra en la que va a residir un tiempo, cultura que más bien es, como vamos descubriendo a medida que se despliega la historia, una diversidad por momentos extremadamente contradictoria de culturas. Pero para ello debemos recorrer la singular e intensa historia contada. Hay una multiplicidad de aspectos de esas otredades que conforman las culturas norteamericanas que van surgiendo poco a poco, pero, desde la perspectiva de Emilio, lo primero que aparece como vía y a la vez como problema para el acceso a ellas es la lengua. Y esto más allá de la competencia y la destreza en el manejo del inglés por parte del profesor visitante contratado. A lo largo de El camino de Ida, pero sobre todo en las Partes I y II -"El accidente" y "La vecina rusa"-, cómo y hasta qué punto podemos comprender realmente la lengua de los otros deviene una sutil y ambigua cuestión, que pone de manifiesto las posibilidades y los límites del encuentro entre unos y otros, entre el yo y los otros, desde el borde de las barreras idiomáticas y el ineludible desafío y trabajo de traducción que siempre están planteando. La narración de Renzi, si bien se encuentra en español, incluye de manera constante palabras y expresiones del inglés norteamericano que ponen en un primer plano la importancia de la lengua y de las acciones discursivas -y las maneras de traducirlas y entenderlas- como clave del relato y de lo que está juego en los diversos niveles de la historia que se cuenta. Conjeturamos que aquí la interacción y el problema de los lenguajes y las fronteras de traducción, de cómo poder captar y comprender los sentidos que los otros manifiestan en otro idioma, es central, porque hace decididamente a la condición de la extranjería, marca un límite inevitable, que sobre todo se refiere a cómo reconocer a esos otros, por más que a veces se aprecie ese límite en detalles puntuales y hasta superfluos.

3 Un ejemplo se lee al principio del relato, cuando la profesora Ida Brown, una de las estrellas académicas de la Taylor University, que es quien ha propuesto a Emilio como Visiting Professor, lo despide tras la primera cena de ambos:

Cuando nos despedíamos en la esquina frente al campus, me apoyó la mano en el brazo y me dijo con una sonrisa:

-En otoño estoy siempre caliente.

Me quedé seco, confundido. Y ella me miró con una expresión extraña, esperó un instante a que yo dijera algo y luego se alejó resueltamente. Tal vez no me había dicho lo que me pareció escuchar ("In the fall I'm always hot"), quizá me había dicho En la caída soy siempre un halcón. Hot-hawks, podría ser. Otoño quería decir semestre de otoño, pero recién empezaba el semestre de primavera. Claro que hot en slang podía querer decir speed y fall en el dialecto de Harlem era una temporada en la cárcel. El sentido prolifera si uno habla con una mujer en una lengua extranjera. Ése fue otro signo del desajuste que se iba a agravar en los días por venir. Suelo ponerme obsesivo con el lenguaje, resabios de mi formación, tengo el oído envenenado por la fonética de Trubetzkoy y siempre escucho más de lo debido, a veces me detengo en los anacolutos o en los sustantivos adjetivados y pierdo el significado de las frases. (Piglia 2013: 21-22) 
El pasaje siguiente es todavía más paradigmático respecto a los enlaces entre una y otra lengua, entre una y otra cultura, lo traducible o intraducible de esos pasajes y la cuestión de la otredad:

Pasé las semanas siguientes lleno de esas extrañas resonancias. El inglés me intranquilizaba, porque me equivoco con más frecuencia de lo que me gustaría y atribuyo a esos equívocos el sentido amenazador que las palabras a veces tienen para mí. Down the street there are pizza huts to go to and the pavement is nice, bluish slate gray. No podía pensar en inglés, inmediatamente empezaba a traducir. En el fondo de la calle hay una pizzería y el asfalto (el pavimento) brilla agradable bajo la luz azulada. (22)

Ida Brown, de otra manera y aun siendo estadounidense, también se siente por momentos una extranjera en su propia cultura, o más bien respecto a ese conjunto de culturas propias que conforman a su país de origen. Por supuesto, en todos sus términos, su extranjería no es tal. Su otredad resulta muy diferente, de otra gradación o matiz, en relación con los que son verdaderamente extranjeros a la cultura estadounidense -como el argentino Renzi o la rusa Nina Andropova-. Ese sentido de distanciamiento de lo propio por parte de Ida se manifiesta de múltiples maneras. En su pasado ya lejano de estudiante de grado universitario, en las décadas de 1960 y 1970, ha sido alguien que interactuaba de modo cada vez más intenso con activistas de minorías sexuales y agrupaciones radicalizadas antisistema contra la cultura dominante de su país. En ese marco, de manera muy discreta en la acción, pero con entusiasmo y admiración ideológica, había interactuado con miembros de la organización Black Panthers, y se había involucrado con el brillante académico y anarquista antindustrialista y antisistema Thomas Munk, estadounidense pero hijo de inmigrantes polacos de modesta clase media. Éste es el hilo que Renzi, en el presente narrado, puede reconstruir sobre la trayectoria de Ida; el presente de académica neomarxista, feminista y dedicada a los estudios culturales, que define al perfil de la mujer, se enlaza con aquel momento en tanto origen de sus posiciones actuales, según lo que dejan entrever las indagaciones de Renzi.

6 A partir de las figuras de Ida y de Emilio se nota que algunas pautas que caracterizan a la extranjería en esta novela la definen a través de las fronteras y de límites, en algunos casos más nítidos, pero en otras muchas circunstancias más bien móviles, translaticios, que pasan entre la ajenidad y la pertenencia a ciertas esferas culturales y sociales, entre unos y otros sujetos, entre unos y otros grupos que actúan en territorios comunes. Para Renzi, Visiting Professor que proviene de otro país (la idea de "otro país" es un tópico de la poética pigliana, recordemos aquel relato autoficcional del mismo título que figura en Prisión perpetua), la percepción e intelección de esas fronteras y límites, a veces tajantes y a veces relativos, resulta muy intensa, por empezar, como resaltamos antes, por sus manifestaciones interidiomáticas. Según Derrida, la percepción de esa manifestación paradigmática de la Otredad que es la extranjería comienza, en efecto, a partir de la diferencia y la semejanza lingüísticas, y de las maneras en que construimos lingüísticamente a ese Otro (1997).

7 Otro personaje crucial para reflexionar acerca de la extranjería y su ambigua inserción en la otra cultura donde se ha instalado -donde ha sido hospedada - es la de Nina Andropova, la vecina de Emilio de quien él se vuelve confidente; no es casual que sea con otra extranjera con quien Emilio adquiera uno de los mayores grados de interacción y comprensión recíprocas. Leemos:

Nina había hecho todos los trabajos imaginables y debió penar dos años antes de conseguir un puesto de profesora de ruso en un college de New Jersey. En 1960 publicó la segunda parte de su monumental biografía (El novelista Tolstói) y ganó la 
cátedra de Literatura en el Departamento de Lenguas Eslavas de la universidad. Aquí había conocido a su marido, el geógrafo ruso Alberto Ostrov, que investigaba sobre la cartografía de los volcanes de la luna en el legendario Institute of Experimental Studies. Pero su adorado Albert había muerto y ella ahora estaba sola, jubilada ya de la enseñanza y enterrada en su libro interminable sobre los últimos años de Tolstói. (102)

Si en los textos de Piglia hay alguno que otro personaje memorable de origen ruso -el falso conde Antón Tokray de Respiración artificial, quien reside en Concordia como un museo viviente que trata de conservar la cultura prerrevolucionaria-, Nina lo supera ampliamente porque se presenta como un personaje complejo, con numerosos matices, que permite revisitar tanto a Lev Tolstói y la literatura rusa cuanto a la singularidad del idioma ruso ("La tendencia del idioma ruso a la expresión mística era un tipo de imperfección ontológica que no aparecía en otras lenguas indoeuropeas" (104)). También permite recordar las transformaciones políticas y socio-culturales que siguen a la Revolución de octubre de 1917 -ella y lo que queda de su familia se deben exiliar tiempo después-, y aun la Europa atravesada por los conflictos ideológicos y culturales de entreguerras y de la posguerra, que Nina evalúa polémicamente, en particular en cuanto a las izquierdas ("Me fui porque no soportaba el clima de la izquierda francesa después de la Liberación, con Sartre, Aragón y otros sátrapas que defendían la represión en Rusia con la hipótesis de que los viejos bolcheviques habían estado objetivamente al servicio del enemigo más allá de sus intenciones" (101)), aunque tampoco se ubica ella misma en la derecha cultural e ideológica: "Seguí pensando que el zar y su corte habían sido los responsables de las catástrofes de Rusia y que la revolución había sido un fuego que destruyó primero a sus héroes y luego aterrorizó a todo el pueblo" (101).

A través de Nina, como ocurre con Ida y otros personajes, la voz narrativa pone en escena, describe, indaga y enlaza reflexivamente momentos político-sociales y artístico-culturales y conflictos ideológicos de diferentes pasados históricos, y los trae al presente. Muy diferentes personajes-voces nos permiten acceder a encuentros y conflictos políticos de luchas entre clases y sectores; a través de ellos y de sus trayectos biográficos ficcionales percibimos el espesor de lo histórico. Incluso la reflexión literaria, decisiva en la configuración discursiva de toda la poética pigliana -tanto de su poética ficcional como de su poética crítica, igualmente relevantes e interactuantes en su programa literario-, se inserta en las digresiones de esa otra extranjera que es Nina:

Tolstói, dijo después, es el más grande de nuestros escritores porque luchó contra esa debilidad de la lengua y en esa lucha, dijo Nina, descubrió la ostranenie. Esa palabrita mágica no tiene traducción, podemos decir distanciamiento, extrañamiento, incluso unheimlich, como Freud, o desfamiliarización. (104)

En El camino de Ida como en Blanco nocturno, novelas que pertenecen a una tercera etapa de la obra de Piglia, se combina entonces una narración fluida con reflexiones y digresiones de diverso tipo, incluso filosóficas, que están a cargo de los personajes ${ }^{2}$, como ya ocurría en otros textos suyos, a veces muy alejados cronológicamente de la novela de 2013. En una de sus conversaciones con Emilio, Nina dice:

Tolstói luchó contra la indomable profundidad demoníaca de la lengua materna, describiendo los detalles mínimos que subsistían bajo la costra metafísica, y de este modo esquivó la trampa de la oscura profundidad religiosa del lenguaje. ¡Su verdadero discípulo fue Wittgenstein! Lo que no se puede decir, no se dice. (105) 
11 Las digresiones de Nina pueden enlazarse a su vez con las de Vladimir Tardewski, el ex filósofo polaco trasplantado a la cultura argentina, otro actor ficcional paradigmático de la extranjería y teorizador de la misma, en Respiración artificial.

La diversidad de extranjeros y su interacción con los nativos se vuelve decisiva en El camino de Ida, y adquiere implicaciones culturales, sociales y políticas como algunas de las antes apuntadas. Pero también se correlaciona con una nueva mirada desplazada, diferente, que la voz-personaje de Renzi ensaya sobre la literatura de la que proviene y sobre las otras literaturas, con un énfasis particular por desarrollarse las acciones de la novela en "otro país". Renzi -y en él la voz autoral-narrativa de Piglia- deconstruye desde ese otro contexto su propia literatura, con mayor razón siendo aquí Renzi -así como Piglia- un escritor a la vez que un académico. Allá, en el contexto estadounidense de los primeros años del gobierno de Bill Clinton, adquiere una singular relevancia el que vuelva su mirada -una mirada otra- sobre una parte del corpus literario argentino. La literatura nacional argentina adquiere otros posibles sentidos y resignificaciones en los recortes, análisis e interpretaciones que el Visiting Professor Renzi desarrolla en el curso que dicta en la imaginaria Taylor University, curso dedicado al escritor Willian Henry Hudson, descendiente de norteamericanos, nacido en Argentina (Quilmes, 4 de agosto de 1841), luego radicado y muerto en Inglaterra (Londres, 18 de agosto de 1922). La relectura de Hudson, desarrollada por Renzi, parecería por momentos recortarse sobre esta afirmación que Piglia escribió en un ensayo sobre la tradición literaria argentina, titulado "La ex - tradición":

La conciencia de la escisión es una clave del concepto mismo de literatura nacional. Se trabaja con dos realidades, en dos contextos, a menudo en dos lenguas. La tradición argentina tiene la forma de un espejismo: en el vacío del desierto se vislumbra lo que se quiere ver. Sarmiento llama a eso la lucha entre la civilización y la barbarie. (Piglia 2014: 149)

El camino de Ida instala precisamente la problemática de las dos realidades, de los dos contextos, de más de dos lenguas, en el centro de su escena ficcional y reflexiva. Y la manera como se reconfigura el escritor Hudson desde esta novela, y en la perspectiva de toda la problemática de la poética pigliana, guarda un estricto correlato con ello.

\section{Un escritor sigiloso desde el siglo XIX}

Dentro de El camino de Ida, la figura y la obra de William Henry Hudson adquieren consistencia en esa lógica de las dos realidades y de las dos o más lenguas, desde donde toma forma el idioma privado que, según el planteo de Piglia, un escritor construye a partir de la lengua de todos. Nacido en Argentina, donde vive entre 1841 y 1869, Hudson se afinca finalmente en Inglaterra, donde terminará de consolidar su extensa trayectoria como escritor y como naturalista y ornitólogo, campo en el cual se destacó tanto en su país de origen como en su país adoptivo. Hudson alimenta con materiales provenientes de tales ámbitos de la realidad los mundos que recrea en la ficción con minuciosidad y conocimiento directo, y a la vez echa luz sobre los rasgos de las comunidades humanas que describe e incluso de las coyunturas históricas de las que resulta testigo -en particular de las culturas de la Argentina que referencia a lo largo de sus relatos y de las tensiones y conflictos sociales que le toca presenciar-.

La figura de autor, la escritura autobiográfica, las ficciones y los datos biográficos de Hudson, reconstruidos también en diálogo con la crítica literaria y cultural, resultan un 
material estructurador en El camino de Ida. Pero esa presencia autoral y de efecto de lectura no es nueva en la poética escritural y crítica de Piglia. Un artículo titulado "Hudson ¿Un Güiraldes inglés?", publicado con la firma de Emilio Renzi en el primer número de la revista Punto de vista en 1978 da cuenta, al principio con reservas, del interés de Piglia por la escritura y la figura de Hudson. Este rescate resulta sugestivo porque permite instalar en un primer plano, desde muy temprano en el proyecto pigliano, discusiones como la de la construcción de una lengua literaria en tanto idioma privado que se constituye entre dos contextos, entre dos o más lenguas, en especial cuando una literatura se escribe en un idioma diferente del que es dominante en ella. En este sentido, conjeturamos que la presencia de Hudson es llamativa para la poética de Piglia desde fines de la década de 1970 y principios de los ochenta, es decir, desde la época de producción y publicación de Respiración artificial, período también de composición de una incisiva escritura ensayística en torno a la literatura argentina visible en los primeros años de Punto de vista, y de comienzo de un decisivo reposicionamiento en el campo intelectual, que se irá manifestando luego, gradualmente, con las sucesivas ediciones de Crítica y ficción a partir de 1986. Hudson sería en ese momento una figura latente: si debemos hablar de escritores argentinos tratados en aquella época por Piglia, no es el autor de La tierra purpúrea quien tiene la presencia más evidente ${ }^{3}$.

Pasados muchos años, Hudson reaparecerá, antes de hacerlo como referencia ficcional en El camino de Ida. En El último lector (2005), a propósito de la pulsión lectora que contradice las dificultades y limitaciones materiales, se cita la alusión de Hudson en Allá lejos y hace tiempo a la circulación de libros entre las familias que se los prestaban desde un campo a otro de la pampa argentina. Allí aparece subrayado el Hudson lector. En El camino de Ida ese perfil se amplía y expande, hasta ser un principio de construcción narrativa y temática, porque en dicha ficción en torno a Hudson se condensan muy diversas cuestiones relevantes en la trama novelesca. Ida ha invitado a Renzi para que dicte un seminario sobre Hudson, porque:

Había leído mis libros, conocía mis proyectos. Quería que diera un seminario sobre Hudson. "Necesito tu perspectiva", dijo con una sonrisa cansada, como si esa perspectiva no tuviera demasiada importancia. Ella estaba trabajando sobre las relaciones de Conrad con Hudson, me dijo, anticipando que ése era su terreno y que no me convenía entrar ahí. (20)

En torno a Hudson se articulan algunos elementos de la vida académica, central en el relato, pero también se hace referencia a una diversidad de concepciones filosóficas y literarias en pugna durante la modernidad, centralmente la que va desde el siglo XVIII al presente, con los efectos del industrialismo, el capitalismo y el posindustrialismo, tanto en los ámbitos urbanos como rurales, tanto en las culturas intelectuales y políticas como en las construcciones culturales de la naturaleza y sus vínculos con la vida civilizada. A partir de Hudson se resignifican diversas series que se pueden leer en la novela. Sin duda, en primer lugar, se resignifica la serie de la revalorización de la naturaleza como lugar de resistencia ante los avances destructivos de la civilización técnica e industrial, lugar donde se posicionó históricamente Hudson (este aspecto se articula con otro elemento decisivo de la novela, no enfocado en particular en este artículo, pero al que aludiremos en el cierre). En segundo lugar, junto a Hudson se resignifica, con matices, a una serie de otros escritores, que son intertextos clave del relato. Es el caso de Conrad, de Melville (objeto de estudio central de D'Amato, el Chairman del Departamento donde Renzi ha ido a enseñar) y de Tolstói, perfilado centralmente a partir del personaje de Nina, pero quien, como sabemos, fue también un agudo crítico de los efectos destructivos de la sociedad 
capitalista en relación a las culturas y tradiciones rurales, una de las razones -además de la de su excelencia literaria- por las que puede conjeturarse que fue uno de los principales escritores de referencia para Hudson, según éste señala en Allá lejos y hace tiempo. En tercer lugar, a partir de Hudson, Conrad y algunos otros -asimismo a partir de Tolstói, según las discusiones entre Nina y Renzi-, se relee a lo largo de la novela aquello que ha desencadenado las presentes consideraciones: el problema de la lengua y la extranjería como una cuestión de otredades, crucial en este tipo de escritores. En efecto, Hudson, escribiendo como Conrad una de las más brillantes prosas de habla inglesa entre los siglos XIX y XX, vuelve una y otra vez en sus diversos textos a referir sobre todo la Argentina, el Río de la Plata y, en general, la parte sur del continente americano, e instala en su escritura el problema de lo extranjero y su relación con los pasajes y fronteras entre lenguas. En esta dirección, la novela de Piglia, a partir de las reflexiones de Renzi y los diálogos con sus colegas y estudiantes, y a partir de aquello que ocurre alrededor y atraviesa ese mundo académico, incita a revalorizar y resignificar el devenir de la escritura y la vida de Hudson. Desde El camino de Ida, una multiplicidad de detalles cruzados -como, por ejemplo, la reflexión de Hudson sobre la blancura de la ballena de Herman Melville en Días de ocio en Patagonia- le otorgan una nueva dimensión a la relectura del autor de Crystal Age.

\section{Entre El agente secreto y el Unabomber}

Si bien no ejerció la enseñanza académica de literatura, al radicarse en Inglaterra Hudson fue, además de escritor y naturalista, un crítico y asesor literario muy valorado por figuras como Arnold Bennett, John Galsworthy y Edward Garnett, siendo este último crucial para el cada vez mayor reconocimiento de Hudson en el mundo literario y editorial de habla inglesa, sobre todo a partir de las publicaciones en inglés de El ombú (1902) y de la novela Mansiones verdes (1904). A partir centralmente de Garnett, la escritura de Hudson, quien se consideraba más un naturalista que un escritor, adquiere un alto reconocimiento de autores como Virginia Woolf, Ezra Pound, Herbert George Wells, Thomas Hardy y Joseph Conrad, amigo personal de Hudson e igualmente relevante en la trama de El camino de Ida. Podría decirse entonces que el nombre de Hudson sugiere el de un escritor y un corpus que serían pretexto ideal para una mirada reflexiva desde la ficción acerca de la dinámica y las tensiones en el mundo académico, tal como ocurre en El camino de Ida. Por este motivo y por la cuestión de las fronteras y tensiones lingüísticas y culturales, su presencia intertextual constituye a nuestro criterio un principio constructivo de la novela, ya sea en cuanto a los tópicos de lo narrado, como a los problemas de escritura y de lenguaje sobre los que vuelven diversos personajes -y Renzi en particular- a lo largo del relato. Precisamente, si en la novela el nombre de Hudson permite revisar el problema del extranjero que contribuye a redefinir la literatura de su "otro país" (desde Inglaterra escribe en inglés pero refiriéndose recurrentemente a América, y en particular a Argentina) y que, en su revalorización mística de la naturaleza, propone una defensa de la misma frente a la amenaza destructiva del industrialismo capitalista, a partir de Conrad se pone en discusión aquella posición artística y filosófica de Hudson enlazándola con una reacción radical ante la sociedad capitalista y contra aquello que se vive como una opresión de la mercancía y lo tecnológico sobre la vida.

En este último aspecto se ha detenido el ensayo de Daniel Balderston (2017). Su interpretación prioriza otro ángulo de examen, que podría ser leído como 
complementario del que aquí tratamos. En este caso, se observa en El camino de Ida una novela atravesada una vez más, como resulta recurrente en el corpus de Piglia, por una tensión irresoluble que transita su poética: la compleja relación entre literatura y política. Lo singular de la novela es cómo aquella tensión se percibe en el mundo académico, en la cultura estadounidense contemporánea y cómo esto se vuelve sobre todo más visible y dramático por la muerte del personaje de Ida, provocada por un explosivo en una acción terrorista, y por una atmósfera de conspiraciones, intrigas y servicios secretos internos en tensión y conflicto dentro de la misma cultura norteamericana -que por esto mismo manifiesta una marcada heterogeneidad-. Balderston señala:

[...] es interesante que el autor se haya decidido a enfocar lo que en el país se llama domestic terrorism: terrorismo "doméstico" o nacional, es decir actos terroristas hechos por ciudadanos estadounidenses, y en este caso por un ciudadano de raíces europeas y con una educación de élite, en universidades de la misma categoría que aquella donde trabajó Piglia. (2017: 310)

\section{Y luego agrega:}

Ida muere en un extraño accidente de auto, y gran parte de la novela es una investigación por parte de Renzi de los posibles motivos de su muerte, investigación que le hace descubrir vínculos inesperados entre ella y Thomas Munk, el nombre que lleva el Unabomber en la novela (la historia de éste no se sigue al pie de la letra -por ejemplo se ejecuta a Munk al final de la novela, mientras Kaczynski sigue vivo en la prisión federal de Florence, Kentucky- pero hay muchos detalles de su historia que sí se toman de su manifiesto y de los escritos en torno a él, sobre todo del libro de Alston Chase Harvard and the Unabomber, de 2003). (310)

Inspirado en el Unabomber realmente existente, a su vez Munk, tal como Balderston lo detalla, es un sutil lector, lector decidido a "[...] la acción que se necesita para completar políticamente las tramas inconclusas de la ficción" (316). Por esto, por su radicalizada oposición al sistema posindustrial, en particular al entrelazamiento de tecnología, política y capitalismo, decide pasar a la acción terrorista, invocando su Manifiesto que, publicado por la prensa, será uno de los elementos que permitirán, luego de varios años de rastreo infructuoso por el FBI, deducir su identidad. Tal como la novela de Piglia indica, y Balderston reordena en su lectura, resultan minuciosos los puntos de contacto inspiradores entre la trama de $E l$ agente secreto de Conrad y la realización de la práctica terrorista por parte de Munk/Kaczynski (la lectura deductiva de los efectos de la acción armada a partir de dicha novela acelera, según se sugiere, el final de Ida Brown). Tales elementos hacen a la trama de novela policial-política, de ficción paranoica o narración del complot, que complementa la otra trama de novela académica y ensayística definida sobre todo en la primera parte de El camino de Ida.

Y aquí vuelve a aparecer Hudson. No solamente por haber sido descendiente de norteamericanos, si bien nacido y luego radicado en dos países diferentes, lo cual instala aquella cuestión mencionada de la extranjería, tan matizada en el texto. Además, porque a través de Conrad, el escritor de la ficción futurista Crystal Age se conecta de alguna manera con planteos filosófico-culturales que guían el accionar del Unabomber, pero solamente como un lejano precursor sutilmente intelectual, sobre todo por la crítica radical a la sociedad hiper industrializada que amenaza la vida natural. Y porque Hudson queda, en todo caso, como una ambigua contracara pacífica en un pasado mediato respecto de otra salida opuesta, la violenta, que finalmente elige Munk ante el estado de las cosas. Lo cual, a su vez, es resaltado -tal como Balderston lo subraya- por la amistad y los vínculos estrechos que en la vida real efectivamente mantuvieron Hudson y Conrad, escritores extremadamente afines, ya sea por su gran atracción por los mundos exóticos a

Cuadernos LIRICO, Hors-série | 2019 
las culturas eurocéntricas que incorporaron a sus ficciones, ya sea por su calidad de extraordinarios prosistas en lengua inglesa, habiendo experimentado diferentes pero intensas experiencias de extranjería respecto a dicha lengua y cultura.

Con lo anterior sugerimos cómo resulta complementario reflexionar desde Hudson a la vez que desde Conrad en torno a la novela de Piglia. Retomando lo señalado en torno a la lengua, la otredad y lo extranjero al principio de este artículo, y las cuestiones que esos temas plantean ante la conciencia reflexiva de Renzi y otros personajes, vemos que tanto Hudson como Conrad las abordaron en su escritura con rasgos singulares. En las obras de estos escritores las tensiones centros/periferias, lo propio/lo ajeno resultaron cruciales y se trataron con gran amplitud y matices. En ambas narrativas lo americano, y puntualmente la América del Sur, han sido territorios, tiempos y espacios recurrentemente abordados. Pero a propósito de la literatura y cultura argentinas, repensadas desde la otredad estadounidense que pone en escena El camino de Ida, Conrad y la serie de problemas artísticos, políticos y culturales en torno a él que circulan por el relato- ingresa y se despliega de la mano de Hudson, porque éste se ha rizomatizado como intertexto clave primero. Juntos, ambos resultan referencias de la novela de Piglia en su conjunto y son en parte principios constructivos de lo narrado y de la organización del texto.

La importancia de Hudson en El camino de Ida es tal que no resulta exagerado afirmar que esta novela argentina es la que postula al fin, desde la ficción, que se reubique el corpus del escritor de La tierra purpúrea en relación con problemas relevantes del sistema literario y la cultura argentina como los mencionados. Esto acompaña una revalorización crítica de Hudson, quizá un tanto tardía por parte de Piglia, manifiesta sobre todo en su ensayo El último lector. Como si dijéramos: en los últimos años, Hudson adquiere la mayor dimensión en la lectura que Piglia realiza, tanto en su poética artística como en su poética crítica, llegando por momentos ese escritor a ser un extranjero tan incidente en la literatura y cultura argentinas como, según Piglia, lo ha sido Witold Gombrowicz. Y decimos tardía porque si bien, como ya puntualizamos, Piglia escribe sobre Hudson desde, al menos, 1978, en ese lejano ensayo todavía lo considera un escritor inglés nacido en "las colonias", que escribe en inglés, un europeo que escribe para europeos, que más bien parece un Ricardo Güiraldes inglés cuya obra pudo ser traducida y asimilada a la cultura argentina en los contextos ideológicos de mitificación conservadora de lo rural entre fines del siglo XIX y principios del XX (Piglia 1978: 23-24) ${ }^{4}$. Por esto mismo, en dicho ensayo, Piglia vincula a Hudson antes con Kipling que con Conrad. Sin descartar cierta validez de aquella lectura, sin duda las valoraciones en torno a Hudson evolucionaron dentro de la misma poética de lectura y de escritura de Piglia y esto es lo que manifiesta con la mayor cantidad de aristas posibles El camino de Ida. Lo cual en definitiva resulta más justo en términos críticos. Porque si bien la lectura ideológica de Piglia en 1978 traza un aspecto ineludible según el cual considerar a Hudson, no hace justa ponderación de la complejidad del tránsito de Hudson entre Argentina, otros territorios de América e Inglaterra, y tampoco da cuenta de que, aun sin dejar de escribir en inglés, en La tierra purpúrea y en El ombú y otros cuentos rioplatenses el escritor pudo captar de manera muy aguda ciertos ecos y detalles de la cultura criolla argentina -la vida de los gauchos, parte de la vida histórica del siglo XIX en América del Sud-, que no arbitrariamente fueron luego valorados por la sagacidad de escritores como Borges y Martínez Estrada ${ }^{5}$. Hudson, un naturalista y escritor argentino a la vez que extranjero que, desde la perspectiva del 
escritor y del lector argentino Ricardo Piglia, instala tanto el problema de la lengua como la cuestión compleja y necesaria del otro.

\section{BIBLIOGRAFÍA}

A.A.V.V., Cien poesías rioplatenses 1800-1950. Antología. Ordenación, prólogo, notas sobre la poesía en el Río de la Plata y bio-bibliográficas de los poetas por Roy Bartholomew. Apéndice con los poemas de William Henry Hudson, Buenos Aires, Raigal, 1954.

Balderston Daniel, "Piglia y el Unabomber: literatura y política en El camino de Ida", Revista Landa, Vol. 2, n 5, Florianópolis, Universidad Federal de Santa Catalina, 2017, p. 378-391. También en Revista La Biblioteca, $\mathrm{n}^{\circ}$ 15, Buenos Aires, 2015.

Bracamonte Jorge, "Treinta años después, Blanco nocturno: otredades, experimentación y relato", Julia Romero (ed.), Las máquinas ficcionales de Ricardo Piglia, Buenos Aires, Corregidor, 2015, p. 145-167.

Conrad Joseph, El agente secreto, Santiago de Chile, Prosa, 1998. Trad. Alberto Martínez Adell. Derrida Jacques, El monolingüismo del otro o la prótesis de origen, Buenos Aires, Manantial, 1997. Trad. de Horacio Pons.

Díaz Quiñones Arcadio, “Ricardo Piglia, los años de Princeton”, Julia Romero (ed.), Las máquinas ficcionales de Ricardo Piglia, Buenos Aires, Corregidor, 2015, p. 169-189.

Hudson William Henry, El ombú y otros cuentos rioplatenses, Buenos Aires-México, Espasa-Calpe Argentina S.A., 1941. Versión española de Eduardo Hillman.

--- Un vendedor de bagatelas, Buenos Aires, Sudamericana, 1946. Trad. de Francisco Uriburu.

--- Far Away and Long Ago, London, J.M. Dent \& Sons Ltd., 1947.

Hudson Guillermo Enrique, Días de ocio en la Patagonia, Buenos Aires, Agepe, 1956. Trad. de Emilio Züberbühler.

--- La tierra purpúrea, Buenos Aires, Kraft, 1956.

--- Allá lejos y hace tiempo. Far Away and Long Ago, Buenos Aires, Peuser, 1958. Trad. de Fernando Pozzo y Celia Rodríguez de Pozzo.

Hudson William Henry, Allá lejos y hace tiempo, Buenos Aires, Kapelusz, 1979. Versión en lengua española, estudio preliminar y notas de Alicia Hebe Viladoms.

Hudson William Henry, Mansiones verdes, Barcelona, Destino, 1991. Trad. y postfacio de Marta Pesarrodona.

Martínez Estrada Guillermo, El mundo maravilloso de Guillermo Enrique Hudson, México, Fondo de Cultura Económica, 1951.

Renzi Emilio [Ricardo Piglia], “Hudson ¿Un Güiraldes inglés?”, Punto de vista n 1, 1978, p. 23-25.

Piglia Ricardo, Respiración artificial, Buenos Aires, Sudamericana, 1988 [1980].

--- Prisión perpetua, Buenos Aires, Sudamericana, 1988. 
--- El último lector, Barcelona, Anagrama, 2005.

--- Teoría del complot, Buenos Aires, Mate, 2007.

--- El camino de Ida, Barcelona, Anagrama, 2013.

--- Antología personal, Buenos Aires, Fondo de Cultura Económica, 2014.

--- La forma inicial. Conversaciones en Princeton, Buenos Aires, Eterna Cadencia, 2015.

--- Los diarios de Emilio Renzi (tomo III). Un día en la vida, Buenos Aires, Anagrama, 2017.

\section{NOTAS}

1. Daniel Balderston destaca que la Taylor University es descrita como "elistista y exclusiva". Esta universidad imaginaria está en el Estado de New Jersey. Allí en realidad está ubicada Princeton University, donde Piglia enseñó con algunas interrupciones durante 25 años a partir de 1987, siendo nombrado Senior Fellow del Council of the Humanities, y en donde se jubiló. Es sabido el conocimiento de la vida estadounidense por parte del escritor, y su admiración por la literatura de ese país. Dentro de su trayectoria académica en Estados Unidos, Piglia enseñó en Harvard, en Davis (California) y en Princeton. Sobre los años en esta última, ver la rememoración de Arcadio Díaz Quiñones (2015: 169-189).

2. En la escritura de Piglia coexisten una poética de escritura con una poética crítica; ambas son igualmente interactuantes y decisivas en la construcción de sus textos, sobre todo a partir de Nombre falso (1975). Respecto a las etapas de su obra, notamos una primera que va desde La invasión (1967) hasta Nombre falso (1975), definida por una renovación sofisticada del realismo; un segundo momento experimental que incluye la obra anterior y Respiración artificial (1980); y una tercera etapa, definida por una recuperación del relato y una combinación de tersura y sigilosa renovación de procedimientos textuales, que arranca en Prisión perpetua (1988), incluye La ciudad ausente y Plata quemada, hasta llegar a Blanco nocturno y El camino de Ida, novelas estas últimas donde además lleva a la práctica sus reflexiones sobre lo policial en tanto ficción paranoica y teoría del complot, entre otras consideraciones (Bracamonte 2015: 166).

3. Entre la vasta obra de Hudson, todavía no enteramente traducida a la lengua española, Roy Bartholomew (A.A.V.V. 1954) destaca: The Purple Land (that England lost) (La tierra purpúrea, 1885), Crystal Age (La edad de cristal, 1887), Argentine Ornithology (Ornitología argentina, 1888-1889, en colaboración con Sclater), The Naturalist in La Plata (El naturalista en la Plata, 1892), Fan. The Story of a Young Girl's Life (Fan. Historia de una niña, 1892), Idle Days in Patagonia (Días de ocio en Patagonia, 1893), Nature in Dowland (La naturaleza en Dowland, 1900), El ombú (1902), Hampshire Days (Días en Hampshire, 1903), Green Mansions (Mansiones verdes, novela de la selva tropical, 1904), A Little Boy Lost ( El niño perdido, 1905), The Land's End (El fin de la tierra, 1906), A foot in England (A pie por Inglaterra, 1909), A Shepherd's Life (Vida de un pastor, 1910), Far Away and Long Ago. History of my Early Life (Allá lejos y hace tiempo. Relatos de mi infancia, 1918), The Book of a Naturalist (El libro de un naturalista, 1919), A Traveller in Little Things (Un vendedor de bagatelas, 1921), A Hind in Richmond Park (Una cierva en el parque de Richmond, 1922). Son éstos sólo algunos títulos que no detallan exhaustivamente sus textos sobre pájaros, en particular los de Argentina e Inglaterra. Ezequiel Martínez Estrada divide la obra de Hudson en libros de Temas de Historia Natural, Temas de la naturaleza y del hombre y Novelas, cuentos, memorias, a lo que habría que agregar sus poemas recopilados por Roy Bartholomew. Sobre detalles de su vida y obra, ver el texto de Martínez Estrada y los diversos prólogos y postfacios citados en las ediciones incluidas en la bibliografía. Entre estos, el postfacio de Marta Pessarrodona a Mansiones verdes también alude al impacto de la lectura de Hudson en 
escritores como Jorge Luis Borges y Guillermo Cabrera Infante, además de su circulación en numerosos autores de habla inglesa contemporáneos suyos.

4. Las consideraciones de Piglia/Renzi en este ensayo de 1978 en Punto de vista son retomadas en parte desde Respiración artifical por Tardewski, al citar éste la teoría de Maggi acerca del "intelectual europeo que, instalado en la Argentina, viene a encarnar el saber universal." (1988: 146)

5. Y esto más allá de que Piglia, ya desde varios lustros antes de la novela de 2013, también realiza apreciaciones elogiosas de la escritura hudsoniana, como la siguiente que pertenece a la entrada del día 6 de febrero de 1978 en Los Diarios de Emilio Renzi, cuando justamente está redactando el citado artículo de Punto de vista: "Veo a Hudson en una trama de europeos aclimatados en el Plata (para usar la expresión de Sarmiento), sus novelas se traducen precisamente con el auge del criollismo. En ese sentido, es una suerte de par de Güiraldes. Y por supuesto es un escritor extraordinario, del nivel de Conrad" (Piglia 2017: 69). No obstante lo cual, en el artículo "Hudson ¿Un Güiraldes inglés?" prevalece, como dijimos, la lectura e interpretación ideológico-cultural, aun cuando por estas anotaciones de los Diarios sabemos que ya por la misma época Piglia era consciente de la posible dimensión artística del escritor de Allá lejos y hace tiempo, tanto para la literatura argentina como para la literatura de lengua inglesa.

\section{RESÚMENES}

Dos aspectos parecen relevantes en El camino de Ida: 1) Las tensiones e intercambios entre lenguas: el valor positivo y también el conflicto que supone estar de modo permanente entre dos o más lenguas y culturas diferentes; 2) Las interrelaciones entre la trama novelesca y la vida y literatura del escritor Guillermo Enrique Hudson -entre otros intertextos-. El artículo pone el acento en estas últimas para evidenciar el sigiloso valor emblemático que aquella otra poética ha tenido para la poética pigliana. A partir de estos aspectos se realiza un análisis y una propuesta de interpretación de un sector de la poética pigliana.

Il y a deux aspects qui méritent considération dans El camino de Ida: 1) Les tensions et les échanges entre langues: la valeur positive et aussi le côté conflictuel du fait de se trouver entre deux ou plusieurs langues et cultures différentes; 2) Les interrelations entre l'intrigue du roman et la vie et l'œuvre de l'écrivain William Henry Hudson - parmi d'autres intertextes-. L'article souligne ces dernières afin de rendre évidente la valeur emblématique, quoique occulte, que la poétique de Hudson détient pour la poétique de Piglia. A partir de l'analyse de ces deux aspects le travail formule une proposition d'interprétation de la poétique de l'Argentin.

Two aspects can be relevant in El camino de Ida: 1) Tensions and interchanges among languages : their positive values and also the conflict of those who are permanently among two or more different languages and cultures; 2) Interrelations between the novel plot and the life and literature of William Henry Hudson -among other intertexts-. The article emphasizes these interrelations to show the secretive emblematic influence of Hudson's poetics on the work of the argentine writer. Considering all those questions the essay proposes an interpretation of somme issues in Piglia's poetics. 
ÍNDICE

Palabras claves: Piglia, Hudson, lenguas, poética, Otredad Keywords: Piglia, Hudson, languages, poetics, otherness Mots-clés: Piglia, Hudson, langues, poétique, altérité

\section{AUTOR}

JORGE BRACAMONTE

IDH, CONICET-Universidad Nacional de Córdoba (Argentina) jabracam@gmail.com 